\title{
Oxidative stress is not associated with vascular dysfunction in a model of alloxan-induced diabetic rats
}

\author{
Estresse oxidativo não está associado à disfunção vascular \\ em um modelo de diabetes induzida por aloxana em ratos
}

\begin{abstract}
Verena Kise Capellini', Caroline Floreoto Baldo', Andréa Carla Celotto', Marcelo Eduardo Batalhão², Evelin Capellari Cárnio², Alfredo José Rodrigues', Paulo Roberto Barbosa Evora'
\end{abstract}

\begin{abstract}
Departamento de Cirurgia e Anatomia, Faculdade de Medicina de Ribeirão Preto, Universidade de São Paulo (FMRP-USP), Ribeirão Preto, SP, Brazil ${ }^{2}$ Departamento de Enfermagem Geral e Especializada, Escola de Enfermagem de Ribeirão Preto, USP, Ribeirão Preto, SP, Brazil
\end{abstract}

Correspondence to:

Paulo Roberto Barbosa Evora Rua Rui Barbosa, 367, ap. 15, 14015-120 - Ribeirão Preto, SP, Brazil

prbevora@netsite.com.br

Received on May/28/2010 Accepted on July/6/2010

\begin{abstract}
Objectives: To verify if an experimental model of alloxan-diabetic rats promotes oxidative stress, reduces nitric oxide bioavailability and causes vascular dysfunction, and to evaluate the effect of $\mathrm{N}$-acetylcysteine (NAC) on these parameters. Methods: Alloxan-diabetic rats were treated or not with NAC for four weeks. Plasmatic levels of malondialdehyde (MDA) and nitrite/ nitrate (NOx), the endothelial and inducible nitric oxide synthase (eNOS and iNOS) immunostaining and the vascular reactivity of aorta were compared among diabetic (D), treated diabetic (TD) and control (C) rats. Results: MDA levels increased in D and TD. NOx levels did not differ among groups. Endothelial eNOS immunostaining reduced and adventitial iNOS increased in $\mathrm{D}$ and TD. The responsiveness of rings to acetylcholine, sodium nitroprusside, and phenylephrine did not differ among groups. Conclusions: NAC had no effect on the evaluated parameters and this experimental model did not promote vascular dysfunction despite the development of oxidative stress. Arq Bras Endocrinol Metab. 2010;54(6):530-9
\end{abstract}

Keywords

Oxidative stress; diabetes; nitric oxide; vascular function; N-acetylcysteine

\section{RESUMO}

Objetivos: Verificar se um modelo experimental de diabetes por aloxana promove estresse oxidativo, reduz a disponibilidade de óxido nítrico e causa disfunção vascular, e avaliar o efeito da N-acetilcisteína (NAC) nesses parâmetros. Métodos: Ratos diabéticos por aloxana foram tratados com NAC por quatro semanas. Níveis plasmáticos de malondialdeído (MDA) e nitrito/ nitrato (NOx), imunomarcação para óxido nítrico sintase endotelial e induzida (eNOS e iNOS) e reatividade vascular da aorta foram comparados entre ratos diabéticos (D), diabéticos tratados (TD) e controles (C). Resultados: O MDA aumentou nos grupos D eTD. O NOx não diferiu entre os grupos. A marcação da eNOS no endotélio reduziu e a da iNOS na adventícia aumentou nos grupos $\mathrm{D}$ e TD. A responsividade dos anéis vasculares à acetilcolina, nitroprussiato de sódio e fenilefrina não diferiu entre os grupos. Conclusões: A NAC não teve efeito sobre os parâmetros avaliados. Esse modelo experimental não promoveu disfunção vascular apesar do desenvolvimento de estresse oxidativo. Arq Bras Endocrinol Metab. 2010;54(6):530-9

Descritores

Estresse oxidativo; diabetes; óxido nítrico; função vascular; N-acetilcisteína

\section{INTRODUCTION}

$\mathrm{V}$ ascular diseases are the main causes of death and disability in people with diabetes (1). Oxidative stress is the ultimate cause of structural and functional changes to vascular cells in diabetic patients, and the superoxide anion $\left(\bullet \mathrm{O}_{2}^{-}\right)$is responsible for the reduced nitric oxide (NO) bioavailability (2). The reaction between $\bullet \mathrm{O}_{2}$ and $\mathrm{NO}$ forms peroxynitrite $\left(\mathrm{ONOO}^{-}\right)(3)$, which is able to promote lipid peroxidation (4). Moreover, ONOO- can oxidize tetrahydrobiopterin $\left(\mathrm{BH}_{4}\right)$, 
leading to a phenomenon known as "nitric oxide synthase (NOS) uncoupling", which in turn results in $\bullet \mathrm{O}_{2}$. synthesis instead of NO production by NOS (5).

Despite the overwhelming evidence of decreased NO bioavailability in diabetes $(3,6)$, investigations regarding vascular reactivity exhibit quite conflicting results, thereby jeopardizing the exact participation of $\mathrm{NO}$ in diabetic dysfunctions. There are many reports showing impaired endothelium-dependent relaxation (7-10), while others demonstrate unaltered (11-13) and even augmented endothelium-dependent relaxation $(14,15)$. Vascular reactivity experiments also provided controversial results when the endotheliumindependent relaxation and the contraction responses of the smooth muscle were evaluated $(8,10,12,16-19)$.

These conflicting data prompted us to investigate whether an experimental model of alloxan-diabetic rats promotes oxidative stress, reduces NO bioavailability, and causes vascular dysfunction. The effects of treatment with $\mathrm{N}$-acetylcysteine (NAC) on the same variables were also examined. NAC, an antioxidant and glutathione precursor, was the drug of choice due to its wide capacity of attenuating oxidative stress in many diseases $(20,21)$.

\section{METHODS}

\section{Animals and induction of diabetes}

Male Wistar rats (200-210 g) were housed on a $12 \mathrm{~h}$ light-dark cycle, under constant temperature $\left(22^{\circ} \mathrm{C}\right)$, and were allowed free access to standard laboratory diet and drinking water. The investigation was approved by the Ethical Animal Committee of the University of São Paulo, Campus of Ribeirão Preto.

Diabetes was induced by a single intravenous tail vein injection of alloxan $(40 \mathrm{mg} / \mathrm{kg}$; Sigma, St. Louis, MO, USA) after a $24 \mathrm{~h}$ fast with water ad libitum. Alloxan was freshly dissolved in $50 \mu \mathrm{L}$ of sodium citrate $(0.05 \mathrm{M}$, $\mathrm{pH} 4.5$ ) immediately before use. An equivalent volume of citrate was administered by the same route to control animals. The rats were considered diabetic if they had glycemia $\geq 200 \mathrm{mg} / \mathrm{dL}$ at 7 days after alloxan injection. Blood glucose levels were determined using a glucometer and glucose test strips (Precision Plus Electrodes, Medisense Products, Bedford, USA) following a 12h fast.

\section{Experimental design}

The animals were randomly assigned to three groups $(\mathrm{n}=10$ each): control $(\mathrm{C})$, diabetic (D), and treated diabetic (TD). NAC (Deg, São Paulo, Brazil) was administered to the TD group in the drinking water for 4 weeks. NAC was freshly dissolved in drinking water, to give a daily intake of $1.4 \mathrm{~g} / \mathrm{kg}$ body weight (22) (average $1.270 \pm 0.202 \mathrm{~g} / \mathrm{kg} /$ day). The experimentation period was ended by anesthetizing the rats with thiopental sodium $(40 \mathrm{mg} / \mathrm{kg}$, intraperitoneal injection; Cristália, São Paulo, Brazil), laparotomy was then performed for blood sampling from the abdominal aorta. Finally, the animal was exsanguinated via abdominal aorta and thoracotomy was performed for thoracic aorta harvesting.

\section{Glycemia and body weight measurements}

Fasting blood glucose (determined as previously described) and body weight were measured immediately before alloxan injection, at 1 week after alloxan injection (when the diabetes was confirmed and the animals were randomly assigned to diabetic groups), and at 5 weeks after alloxan injection (end of the treatment period).

\section{Plasma malondialdehyde measurement}

Arterial blood samples were collected in tubes containing EDTA. After blood centrifugation $(3000 \times \mathrm{g}, 10$ $\min , 4^{\circ} \mathrm{C}$ ), plasma aliquots were removed and stored at $-70^{\circ} \mathrm{C}$ until analysis. Plasma malondialdehyde (MDA) concentration was measured using a commercially available kit (Lipid Peroxidation Assay kit, Calbiochem, San Diego, CA, USA). The assay is based on the ability of a chromogenic agent to react with MDA, yielding a stable chromophore with maximal absorbance at $586 \mathrm{~nm}$.

\section{Plasma nitrite and nitrate levels}

Arterial blood samples were collected in tubes containing heparin. After blood centrifugation $(3000 \times \mathrm{g}, 10$ $\min , 4^{\circ} \mathrm{C}$ ), plasma aliquots were removed and stored at $-70^{\circ} \mathrm{C}$. Samples were analyzed in duplicates for nitrite and nitrate (NOx) using an ozone-based chemiluminescence assay. Briefly, the plasma samples were treated with cold ethanol ( 1 volume of plasma: 2 volumes of ethanol for $30 \mathrm{~min}$ at $\left.-20^{\circ} \mathrm{C}\right)$ and centrifuged $(4000 \times \mathrm{g}$, $10 \mathrm{~min}$ ). NOx levels were measured by injecting $25 \mu \mathrm{L}$ of the supernatant in a glass purge vessel containing $0.8 \%$ of Vanadium (III) in $\mathrm{HCl}(\mathrm{l} \mathrm{N})$ at $90^{\circ} \mathrm{C}$, which reduces $\mathrm{NOx}$ to $\mathrm{NO}$ gas. A nitrogen stream was bubbled through the purge vessel containing Vanadium (III), then through $\mathrm{NaOH}(\mathrm{l} \mathrm{N})$, and then into an NO analyzer $\left(\right.$ Sievers ${ }^{\circledR}$ Nitric Oxide Analyzer 280, GE Analytical Instruments, Boulder, CO, USA). 
Immunohistochemical assay for endothelial and inducible nitric oxide synthases

Thoracic aortic samples were immediately fixed in $10 \%$ buffered formalin solution for $24 \mathrm{~h}$ and embedded in paraffin. Paraffin-embedded tissue blocks were sectioned at $3 \mu \mathrm{m}$. The sections were processed for endothelial nitric oxide synthase (eNOS) and inducible nitric oxide synthase (iNOS) staining using a commercially available kit (DAKO LSAB ${ }^{\circledR}$ Kit, Peroxidase for use on RAT Specimens, DAKO Corporation, Carpinteria, CA, USA). In brief, the sections were fixed to slides pretreated with [3-aminopropyl]triethoxysilane (Sigma, St. Louis, MO, USA). Subsequently, the sections were deparaffinized and rehydrated through a descending alcohol series followed by distilled water. In sequence, the endogenous peroxidase activity was inactivated with hydrogen peroxide, and the sections were incubated with citrate buffer in a humidified heat chamber (Optisteam Plus, Krups North America Inc., New Jersey, USA) for antigen retrieval. The non-specific bindings were blocked with swine normal serum. The sections were incubated with polyclonal eNOS antibody (NOS3 (H-159): sc-8311, Santa Cruz Biotechnology, California, USA) at a dilution of $1: 25$ or monoclonal iNOS antibody (NOS2 (C-11): sc-7271, Santa Cruz Biotechnology, California, USA) at a dilution of 1:5. In sequence, the sections were incubated with secondary antibody of $\mathrm{LSAB}^{\circledR 2}$ kit and then with the streptavidin peroxidase of the same kit. Finally, the reactions were revealed with 3,3'-diaminobenzidine tetrahydrochloride (Sigma, St. Louis, MO, USA), and the sections were counterstained with Harris' haematoxylin. As negative controls, sections were processed with the above procedures, but the primary or secondary antibodies were omitted.

All slides were observed and photographed with a high definition camera (AxioCam HRc, Zeiss, Germany) coupled to a microscope (Axioskop 2 plus, Zeiss, Germany). The immunostaining was graduated in 4 classes $(0-$ when the tissue was not marked, as in negative controls, 1 - when the tissue was marked lightly, 2 - when the tissue was marked moderately, and 3 - when the tissue was marked densely) by an observer blind to the animal group.

\section{Morphometric analysis of the thoracic aorta medial layer}

Thoracic aorta samples were immediately fixed in $10 \%$ buffered formalin solution for $24 \mathrm{~h}$ and embedded in paraffin. Paraffin-embedded tissue blocks were sectio- ned at $3 \mu \mathrm{m}$, and sections were stained with Masson's trichrome. With the use of a high definition camera (AxioCam HRc, Zeiss, Germany) coupled to a microscope (Axioskop 2 plus, Zeiss, Germany), all slides were photographed in such a way that the vascular ring fitted a unique image. The area and the mean thickness of the thoracic aorta muscular layer were measured by an observer unaware of the animal group by means of the KS400 - Carl Zeiss version 2.0. To obtain the area of the muscular layer, each vascular ring was submitted to manual exclusion of the adventitia and perivascular tissues by the use of the "eraser" tool after zooming in. In sequence, the mean thickness of the muscular layer was obtained by choosing the lines (vertical, horizontal, or radial) that best fitted the vascular ring according to its orientation on the slide.

\section{Vessel preparation and isometric tension recording}

The thoracic aorta was carefully dissected free of connective tissue and immersed in a cooled and oxygenated Krebs solution $\left(\mathrm{NaCl}\right.$ : 118.0, $\mathrm{KCl}: 4.7, \mathrm{CaCl}_{2}: 2.5$, $\mathrm{KH}_{2} \mathrm{PO}_{4}: 1.2, \mathrm{MgSO}_{4}: 1.66$, glucose: 11.1, $\mathrm{NaHCO}_{3}$ : $25.0(\mathrm{mM}), \mathrm{pH} 7.4)$. Ring segments of the thoracic aorta ( $4 \mathrm{~mm}$ in length) were prepared with great care, so as not to touch the intimal surface. In some segments the endothelium was removed by gently rubbing the intimal surface of the blood vessel with a pair of watchmaker's forceps. This procedure removes endothelium but does not affect the ability of the vascular smooth muscle to contract or relax.

Thoracic aorta segments were mounted in organ chambers $(10 \mathrm{~mL})$ filled with Krebs solution maintained at $37^{\circ} \mathrm{C}$ and bubbled with $95 \% \mathrm{O}_{2} / 5 \% \mathrm{CO}_{2}(\mathrm{pH} 7.4$ ). Each arterial ring was suspended by two stainless steel clips placed through the lumen. One clip was anchored to the bottom of the organ chamber, while the other was connected to a strain gauge for measurement of the isometric force using Grass FT03 (Grass Instrument Company, Quincy, MA, USA). The rings were placed at an optimal length-tension of $1.5 \mathrm{~g}(10,12)$ and allowed to equilibrate for 60 minutes with the bath fluid being changed every 15 to 20 minutes. Endothelial integrity was assessed qualitatively by the degree of relaxation caused by acetylcholine (Ach, $10^{-6} \mathrm{M}$; Sigma, St. Louis, MO, USA) in the presence of contractile tone induced by phenylephrine (Phe, $10^{-7} \mathrm{M}$; Sigma, St. Louis, MO, USA). For studies of endothelium intact vessels, the ring was discarded if relaxation with Ach was not $80 \%$ or greater. For studies of endothelium-denuded vessels, 
rings were discarded if there was any measurable degree of relaxation. Sequentially, each ring was washed and reequilibrated for $30 \mathrm{~min}$. Aortic rings were then precontracted with Phe $\left(10^{-7} \mathrm{M}\right)$, and cumulative concentration-response curves were obtained after a stable plateau was reached. The endothelium-dependent relaxation was evoked by Ach $\left(10^{-10}-10^{-5} \mathrm{M}\right)$ in intact aortic rings, while the endothelium-independent vasorelaxation was evoked by sodium nitroprusside (SNP, $10^{-10}-10^{-5} \mathrm{M}$; Sigma, St. Louis, MO, USA) in denuded rings. Cumulative concentration-response curves for Phe $\left(10^{-10}-10^{-5} \mathrm{M}\right)$ were determined on endothelium-intact and -denuded aortic rings. Concentration-response curves were also accomplished by pre-incubating the vascular rings with $\mathrm{N} \omega$-nitro-L-arginine methyl ester (L-NAME, $10^{-4} \mathrm{M}$, a non-specific NOS inhibitor; Calbiochem, San Diego, CA, USA) for 50 minutes.

\section{Statistical analysis}

Statistical two-way repeated-measures ANOVA and Bonferroni post-test data evaluations were performed using the program SPSS 15.0 (Apache Software Foundation, 2000). Values were considered to be statistically significant at $\mathrm{p}$ values less than 0.05 .

\section{RESULTS}

\section{Glycemia and body weight}

The initial glycemia and body weight did not differ among the groups. After the alloxan injection, diabetic and treated diabetic rats presented higher fasting blood glucose and lower body weight than control animals $(\mathrm{p}<0.001)$. NAC treatment did not affect glycemia or body weight compared with diabetic animals without treatment (Table 1$)$.

\section{Plasma MDA and NOx levels}

At the end of the 4-week treatment, plasma MDA levels were significantly higher in diabetic $(\mathrm{p}=0.003)$ and treated diabetic animals $(\mathrm{p}=0.015)$ than those in the control group. At the end of the same period, plasma NOx levels did not differ among the groups. Administration of NAC did not change plasma MDA or NOx levels compared with diabetic rats without treatment (Table 2).

\section{eNOS and iNOS immunohistochemical analysis}

The intensity of positive eNOS immunostaining decreased in the thoracic aorta endothelium of diabetic and treated diabetic rats compared with age-matched control rats $(\mathrm{p}=0.007)$. However, NAC treatment did not affect the eNOS immunostaining in the endothelium. In the muscular layer, the eNOS immunostaining ranged from light to moderate and there were no differences among the three groups. In the adventitia, no positive immunostaining for eNOS was observed in any group (Table 3, Figure 1A).

In the endothelial and smooth muscle layers of thoracic aorta, the iNOS immunostaining was not evident in any group. However, the intensity of positive iNOS immunostaining increased in the adventitia of diabetic and treated diabetic rats compared with their age-matched control rats $(\mathrm{p}<0.001)$. Again, NAC treatment did not affect the iNOS immunostaining (Table 3, Figure 1B).

\section{Thoracic aorta muscular layer area and mean thickness}

The area of the thoracic aorta smooth muscle of diabetic and treated diabetic animals decreased compared with control $(\mathrm{p}=0.001$ and $\mathrm{p}<0.001$, respectively). Moreover, NAC treatment promoted a reduction in the area of aorta medial layer of treated diabetic compared with non-treated diabetic rats $(\mathrm{p}=0.029)$ (Table 4$)$.

Table 1. Fasting blood glucose and body weight in control, diabetic and treated diabetic rats

\begin{tabular}{llccc}
\hline & & Control & Diabetic & Treated diabetic \\
\hline Fasting glucose $(\mathrm{mg} / \mathrm{dL})$ & Day of alloxan injection & $92.60 \pm 8.87$ & $90.10 \pm 8.99$ & $87.40 \pm 16.15$ \\
& 1 week after alloxan injection & $90.10 \pm 8.99$ & $364.47 \pm 53.18^{\star}$ & $352.33 \pm 56.94^{\star}$ \\
& 5 weeks after alloxan injection & $85.27 \pm 8.73$ & $435.83 \pm 53.00^{\star}$ & $401.67 \pm 54.28^{\star}$ \\
Body weight (g) & Day of alloxan injection & $190.70 \pm 16.81$ & $199.80 \pm 11.99$ & $198.36 \pm 6.45$ \\
& 1 week after alloxan injection & $312.60 \pm 20.66$ & $216.42 \pm 36.97^{\star}$ & $200.39 \pm 26.73^{\star}$ \\
& 5 weeks after alloxan injection & $514.71 \pm 24.72$ & $220.21 \pm 67.97^{\star}$ & $205.54 \pm 42.52^{\star}$ \\
\hline
\end{tabular}

Values were obtained previous and after alloxan-induced diabetes in diabetic and treated diabetic rats or vehicle administration in control rats. All values are means $\pm S D(n=10)$. ${ }^{*}<0.001$ vs. control (One-way ANOVA, Bonferroni's Multiple Comparison Test). 
Table 2. Plasma MDA and NOx levels in control, diabetic and treated diabetic rats

\begin{tabular}{lccc}
\hline & Control & Diabetic & $\begin{array}{c}\text { Treated } \\
\text { diabetic }\end{array}$ \\
\hline MDA $(\mu \mathrm{M})$ & $4.45 \pm 1.57$ & $8.71 \pm 2.42^{*}$ & $9.44 \pm 3.31^{\#}$ \\
NOx $(\mu \mathrm{M})$ & $30.28 \pm 4.67$ & $28.68 \pm 11.06$ & $48.55 \pm 31.00$ \\
\hline
\end{tabular}

Values were obtained 5 weeks after alloxan-induced diabetes in diabetic and treated diabetic rats or vehicle administration in control rats. All values are means $\pm S D(n=10)$. * $p=0.003$ vs. control, ${ }^{*} p=0.015$ vs. control (One-way ANOVA, Games-Howell's Multiple Comparison Test).
Table 3. Degree of eNOS and iNOS immunostaining in the three layers of thoracic aorta of the control, diabetic and treated diabetic rats

\begin{tabular}{lcccc}
\hline & & Control & Diabetic & $\begin{array}{c}\text { Treated } \\
\text { diabetic }\end{array}$ \\
\hline Degree of eNOS & endothelium & $2.56 \pm 0.53$ & $1.61 \pm 0.66^{*}$ & $1.64 \pm 1.01^{*}$ \\
immunostaining & muscle & $1.78 \pm 0.83$ & $1.65 \pm 0.65$ & $1.50 \pm 0.52$ \\
& adventitia & 0 & 0 & 0 \\
Degree of iNOS & endothelium & 0 & 0 & 0 \\
immunostaining & muscle & 0 & 0 & 0 \\
& adventitia & 0 & $3^{*}$ & $3^{*}$ \\
\hline
\end{tabular}

The values were attributed according to immunostain intensity. All values are means \pm SD $(n=10) .{ }^{*} p=0.007$ vs. control, ${ }^{*} p<0.001$ vs. control (Kruskal-Wallis Test).

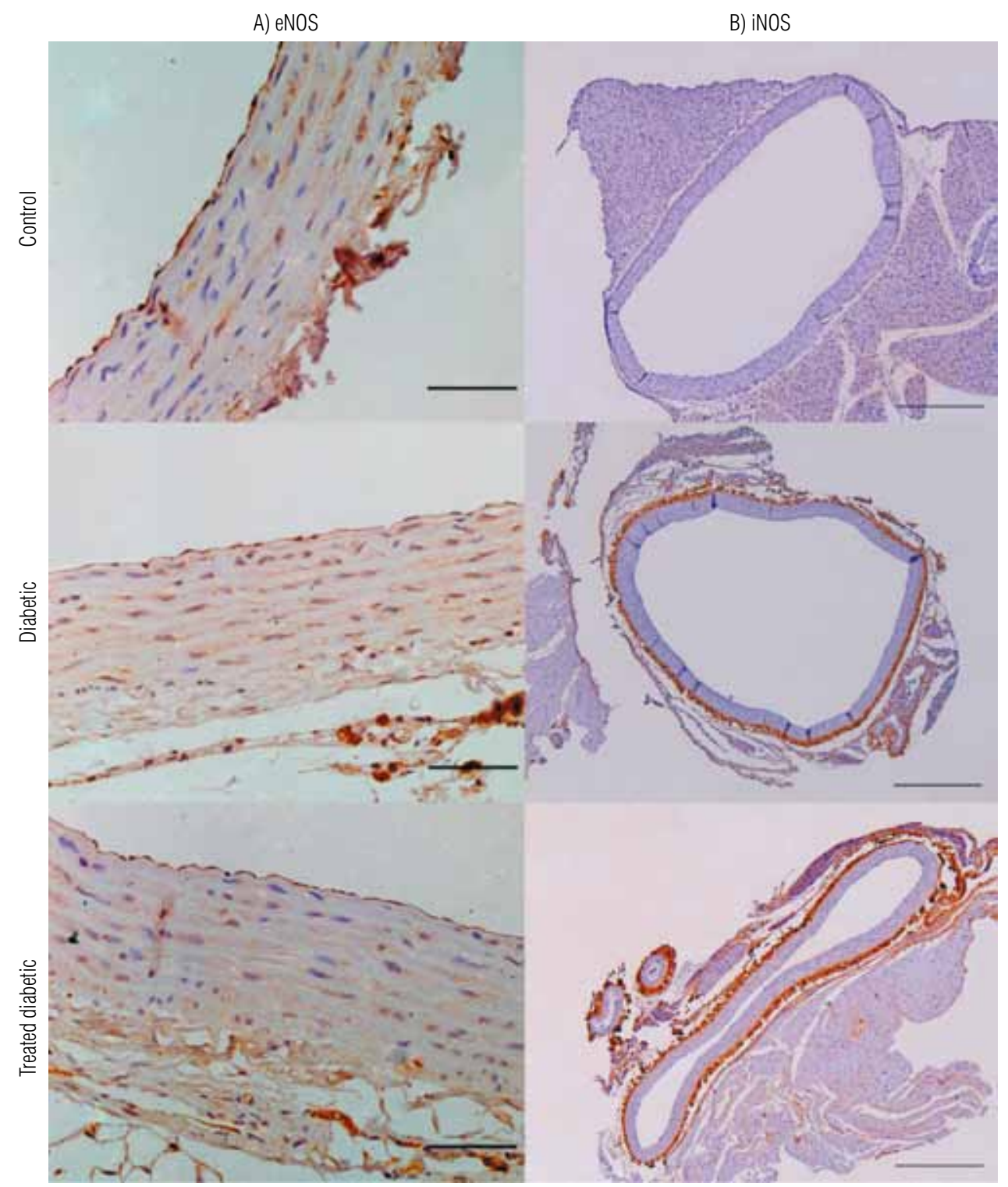

Figure 1. Photomicrography of thoracic aorta of control, diabetic, and treated diabetic animals. A) Endothelial nitric oxide synthase (eNOS) immunostaining: note that the three vessel layers were stained; however; the eNOS immunostaining is decreased in the endothelium of diabetic rats, treated or not (scale bar $=100 \mu \mathrm{m}$ ). B) Inducible nitric oxide synthase (iNOS) immunostaining: observe that only the adventitia of diabetic and treated diabetic rats was stained (scale $\mathrm{bar}=0.5 \mathrm{~mm})$. 
Table 4. Area and mean thickness of thoracic aorta muscular layer in control, diabetic and treated diabetic rats

\begin{tabular}{lccc}
\hline & Control & Diabetic & $\begin{array}{c}\text { Treated } \\
\text { diabetic }\end{array}$ \\
\hline Area $\left(\mathrm{mm}^{2}\right)$ & $2.48 \pm 0.48$ & $1.62 \pm 0.18^{\dagger}$ & $1.08 \pm 0.50^{\star *}$ \\
Mean thickness $(\mathrm{mm})$ & $0.14 \pm 0.02$ & $0.09 \pm 0.01^{*}$ & $0.09 \pm 0.00^{\star}$ \\
\hline
\end{tabular}

All values are means $\pm S D(n=10) .{ }^{\dagger} p=0.001$ vs. control, ${ }^{*} p<0.001$ vs. control, ${ }^{t} p=0.029$ vs. diabetic (One-way ANOVA, Games-Howell's Multiple Comparison Test).

The mean thickness of the thoracic aorta muscular layer was also lower in diabetic and treated diabetic animals compared with age-matched controls $(\mathrm{p}<0.001)$. However, administration of NAC had no effect on the mean thickness when diabetic rats were compared with treated diabetic animals (Table 4 ).

\section{Thoracic aorta vascular function}

In the relaxation study, changes in vascular wall tension were expressed as a percent of the relaxation of the maximal contraction following exposure to Phe, a convention that corrects inter-animal variability in the response of the tissue to the drug.

In the contraction study, changes in vascular wall tension were expressed as $\mathrm{g}$ of tension/dry weight $(\mathrm{mg})$ of the aorta ring that generates the respective curve. This convention avoids measurement errors that may arise from inter-animal variability to the amount of tissue.

\section{Endothelium-dependent relaxation}

Ach caused concentration-dependent relaxation of the endothelium-intact aortic rings of the 3 groups in the absence of any inhibitor $(\mathrm{p}<0.001)$ (Figure $2 \mathrm{~A})$ and in the presence of L-NAME (C: $\mathrm{p}=0.007 ; \mathrm{D}: \mathrm{p}=0.001$; TD: $\mathrm{p}<0.001$ ) (Figure 2B).

In inter-group comparisons, no statistical differences were observed among groups when the concentrationresponse curves were achieved without NOS inhibition (Figure 2A). However, after L-NAME incubation, the endothelium-intact rings of diabetic and treated diabetic rats relaxed more than the rings obtained from control animals ( $\mathrm{p}=0.020$ and $\mathrm{p}=0.025$, respectively); moreover, there was no statistical difference between treated and non-treated diabetic animals (Figure 2B).

\section{Endothelium-independent relaxation}

SNP caused concentration-dependent relaxation of endothelium-denuded aortic rings irrespective of group $(\mathrm{p} \leq 0.001)$, with no inter-group statistical differences (Figure 3).
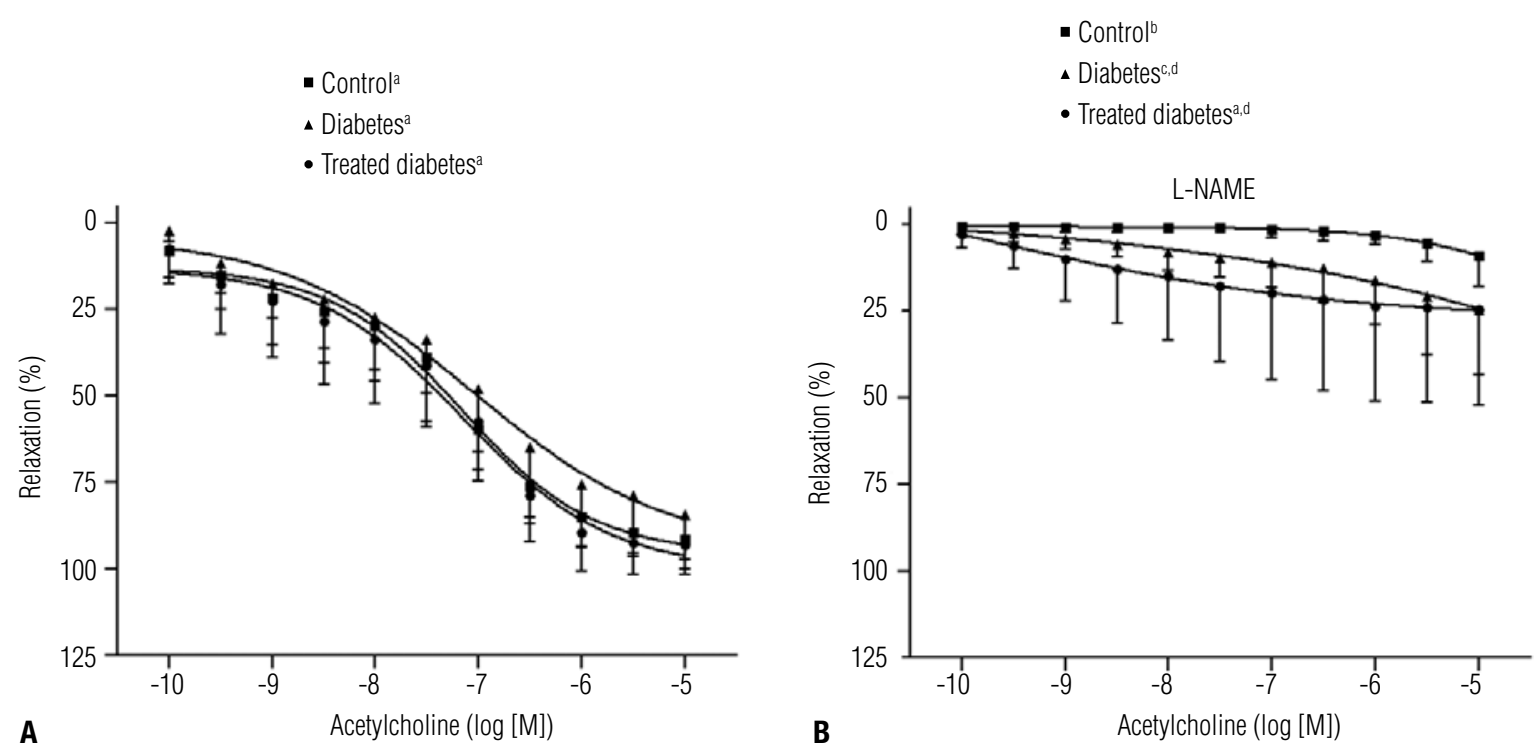

Figure 2. Vasodilator responses of rat thoracic aorta segments of control, diabetic, and treated diabetic groups. Phenylephrine-preconstricted aorta rings with endothelium were relaxed with cumulative concentrations of acetylcholine in the absence (A) and in the presence of L-NAME (B). All values are means $+\mathrm{SD}(\mathrm{n}=10) .{ }^{\mathrm{a}} \mathrm{p}<0.001$ in within-group comparison; ${ }^{b} p=0.007$ in within-group comparison; ${ }^{c} p=0.001$ in within-group comparison; ${ }^{d}$ statistical difference compared to control ( $C$ vs. D: $p=0.020$ and C vs. TD: $p=0.025$ ). Repeated measures two-way ANOVA, Greenhouse-Geisser Test (intra-group comparison), Games-Howell Test (inter-group comparison). 


\section{Contraction study}

Phe caused concentration-dependent contraction of denuded aortic rings (Figure 4A) and endotheliumintact rings, pre-incubated or not with L-NAME (Figure $4 \mathrm{~B})$ irrespective of group $(\mathrm{p}<0.001)$ and with no inter-group statistical differences (Figures $4 \mathrm{~A}$ and $4 \mathrm{~B}$ ).

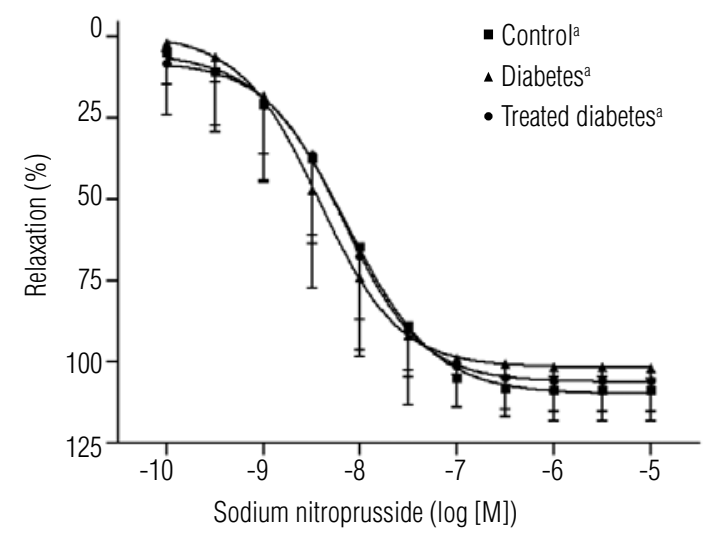

Figure 3. Vasodilator responses of rat thoracic aorta segments of control, diabetic, and treated diabetic groups. Phenylephrine-preconstricted aorta rings without endothelium were relaxed with cumulative concentrations of sodium nitroprusside. All values are means $+S D(n=10)$. ${ }^{\text {a }} p \leq 0.001$ in within-group comparison. Repeated measures two-way ANOVA, Greenhouse-Geisser Test (intra-group comparison), Games-Howell Test (inter-group comparison).

\section{DISCUSSION}

The alloxan-induced diabetes model in rats has been widely employed (23-26), and the present study reinforces the ability of this diabetogenic drug to promote experimental diabetes in rats since the animals presented hyperglycemia and reduced body weight, as observed by many authors $(8,10,12,18)$.

As already mentioned, hyperglycemia induces oxidative stress. This relationship has been demonstrated in many investigations, including our study. Increased levels of MDA or other biomarkers of oxidative stress have been observed in humans with type $1(27)$ and type 2 diabetes (28) and in experimental models of type $1(12,18,25,29)$ and type 2 diabetes $(16,30,31)$. Taking this into consideration, NAC treatment aiming at reduced MDA levels represents a promising therapeutic opportunity. But, in spite of many reports reassuring its beneficial effect on oxidative stress (22,32-34), our study has failed to reduce MDA concentrations. We do not have a clear understanding about the reason why NAC treatment did not restore normal MDA levels, but we hypothesize that this failure could be related to NAC dose or late onset of NAC treatment. However, lower doses of NAC normalized ROS production in streptozotocin-diabetic rats (35), and NAC treatment initiated one week after diabetes induction also nor-
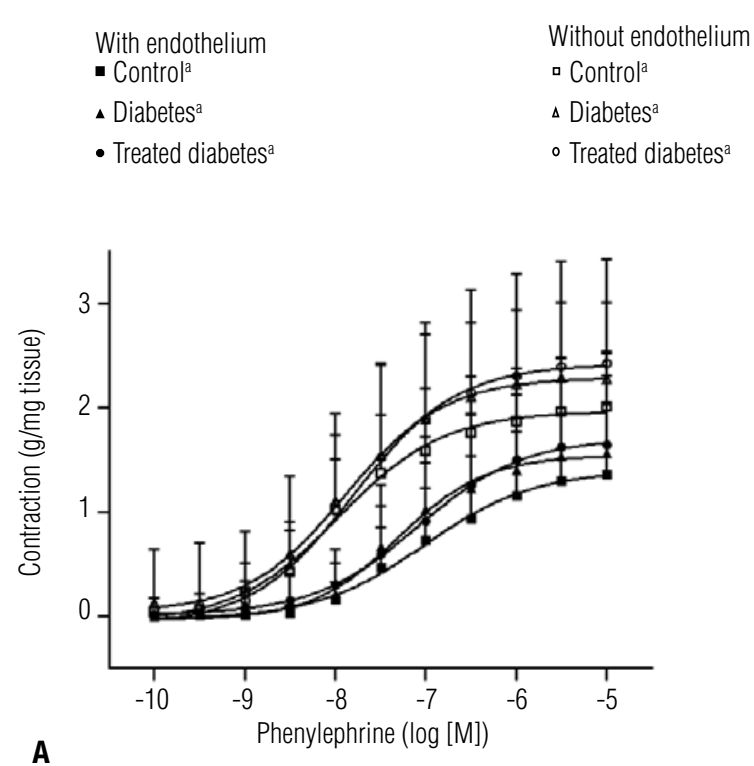

With endothelium With L-NAME

$\times$ Control $^{a}$

+ Diabetes $^{\mathrm{a}}$

* Treated diabetes ${ }^{\mathrm{a}}$

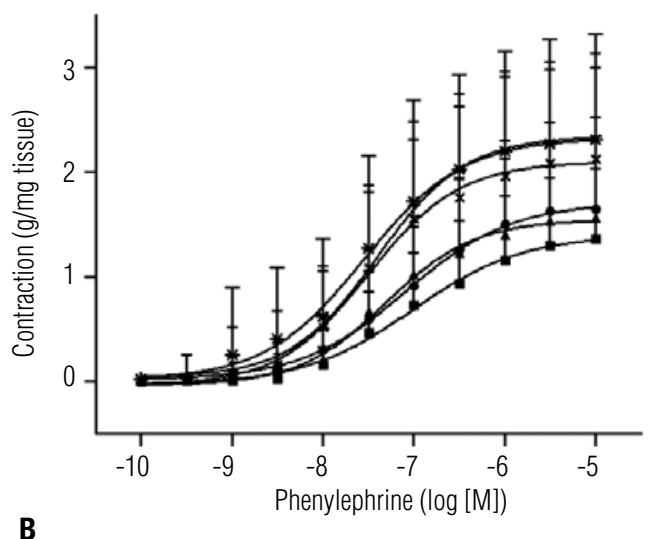

B

Figure 4. Concentration-response curves for phenylephrine in rat thoracic aorta segments of control, diabetic, and treated diabetic groups. A) Concentrationresponse curves were obtained from endothelium intact (full symbols) and denuded-rings (open symbols). B) Concentration-response curves were obtained from endothelium intact-rings before and after L-NAME incubation. All values are means $+S D(n=10)$. a $p<0.001$ in within-group comparison. Repeated measures two-way ANOVA, Greenhouse-Geisser Test (intra-group comparison), Games-Howell Test (inter-group comparison). 
malized the plasma and tissue levels of oxidative stress markers in streptozotocin-diabetic rats (34). Thus, another hypothesis to explain NAC failure in this study would be the diabetogenic agent used here, since all researches reviewed by us demonstrated reduction in oxidative stress after NAC treatment when streptozotocin was employed as a diabetogen. Furthermore, the activity of the $\gamma$-glutamylcysteine syntethase, the enzyme responsible for glutathione synthesis, was reduced in liver alloxan-diabetic rabbits, accounting for reduced glutathione concentrations (36). If this is so, reduced synthase activity may blunt the NAC antioxidant effect.

Increased oxidative stress is known to reduce $\mathrm{NO}$ bioavailability in diabetes $(3,6)$. Indeed, researches that measure $\mathrm{NO}$ or its products and $\bullet \mathrm{O}_{2}$ in endothelial cell culture (37), vessels $(16,30)$, or plasma (38) have demonstrated an inverse relationship between $\mathrm{NO}$ and ROS in hyperglycemic conditions. However, plasma NOx levels did not differ among groups in our study, despite the presence of enhanced plasma MDA concentrations in diabetic rats. One reasonable explanation for this apparent contradiction of normal NOx levels in the presence of increased oxidative stress in diabetic rats is the incomplete inactivation of NO by ROS. This hypothesis is based on the inherent capacity of iNOS to produce greater amounts of $\mathrm{NO}$ (in the order of nanomols to micromols) (39) and on the fact that the aorta from our diabetic animals, treated or not, presented increased intensities of immunostaining for iNOS. Therefore, despite a reduction in eNOS immunostaining in the endothelium from the aorta of diabetic rats, which was observed by other authors $(40,41)$, the increase in iNOS immunostaining could have made sufficient NO available to exert its biological effects. These ideas were also defended by Bojunga and cols., who had similar results (42).

Another result that reinforces our suggestion that NO bioavailability was not reduced in diabetic animals is the normal response of endothelium-intact rings from these animals to Ach, even after NOS inhibition. We also verified that after L-NAME incubation the endothelium-intact rings from diabetic rats, treated or not, presented a higher relaxing response to Ach than the control rings. However, we do not have sufficient data to affirm that this enhanced endothelium-dependent relaxation of the aorta from diabetic rats can be due to larger NO bioavailability, which was suggested as a possible vascular damaging agent in experimental diabetes (42). In addition, we cannot forget that other factors, such as the prostacyclin and the endothelium-derived hyperpolarizing factor can participate in relaxation.

Our results also show that this model of diabetes does not induce vascular smooth muscle dysfunction, neither endothelium-independent relaxation nor contraction aortic capability presented alterations. Previous reports also demonstrated unchanged vascular smooth muscle responsiveness to $\mathrm{NO}$ and (nor)adrenergic agonists in diabetic rings $(10,12,43)$. Indeed, the investigations that observed enhanced vascular smooth muscle responsiveness to contracting agents related it to impaired endothelial NO synthesis during the evocation of a contraction $(18,19)$. However, our graphs show that both NOS inhibition and endothelium removal resulted in the same effect: an increase in contracting response, leading to the supposition that $\mathrm{NO}$ availability was not impaired in this model of experimental diabetes.

We also observed that the area and the mean thickness of the muscular layer of the aorta were decreased in diabetic rats, treated or not, which is compatible with the lower body weights of these animals and emphasizes the need for adopting a correction factor for concentration-response curve comparisons. The treated diabetic animals presented lower aortic smooth muscle area than non-treated diabetic rats, but we believe that this difference can be assumed as an artifact. This suggestion is based on the fact that all vascular segments obtained from treated diabetic animals collapsed when immersed in formalin. However, the mechanism or the reaction that leads to this collapse is unknown.

The possible explanations given for the development or not of vascular dysfunction in diabetes can be related to different glucose concentrations in the media during the vascular reactivity study (44), the duration of diabetes, the vascular bed (44-46), and the studied species $(44,45)$. We credit the failure in the vascular dysfunction development of our model to insufficient diabetes duration, which was reinforced by a recent report showing that diabetes lasting 4 weeks does not promote vascular dysfunction, whereas diabetes lasting 8 weeks causes endothelium-dependent and independent relaxation impairment (17).

\section{CONCLUSION}

In summary, the experimental model of alloxan-induced diabetes in rats lasting 5 weeks is effective for the development of diabetes and oxidative stress but fails to promote vascular dysfunction. NAC administration for 
4 weeks to these diabetic animals does not reduce oxidative stress, change NOx levels, or alter vascular function.

Acknowledgments: We thank Sandra Lúcia Balero Penharvel Martins, Antônio Renato Meirelles e Silva, José Carlos Vanni, Sebastião Assis Mazzetto and Paulo Alves Jr. for technical support, and Coordenação de Aperfeiçoamento de Pessoal de Nível Superior (Capes) and Fundação de Apoio ao Ensino, Pesquisa e Assistência do Hospital das Clínicas da Faculdade de Medicina de Ribeirão Preto da Universidade de São Paulo (FAEPA-HC/ FMRP) for financial support.

Disclosure: no potential conflict of interest relevant to this article was reported.

\section{REFERENCES}

1. Creager MA, LuscherTF, Cosentino F, Beckman JA. Diabetes and vascular disease: pathophysiology, clinical consequences, and medical therapy: Part I. Circulation. 2003;108(12):1527-32.

2. Capellini VK, Celotto AC, Baldo CF, Olivon VC, Viaro F, Rodrigues AJ, Evora PR. Diabetes and vascular disease: basic concepts of nitric oxide physiology, endothelial dysfunction, oxidative stress and therapeutic possibilities. Curr Vasc Pharmacol. [Epub ahead of print]

3. Nishikawa T, Edelstein D, Du XL, Yamagishi S, Matsumura T, Kaneda $Y$, et al. Normalizing mitochondrial superoxide production blocks three pathways of hyperglycaemic damage. Nature. 2000;404(6779):787-90.

4. Wajchenberg BL. Disfunção endotelial no diabetes do tipo 2. Arq Bras Endocrinol Metab. 2002;46(5):514-19.

5. Satoh M, Fujimoto S, Haruna Y, Arakawa S, Horike H, Komai N, et al. $N A D(P) H$ oxidase and uncoupled nitric oxide synthase are major sources of glomerular superoxide in rats with experimental diabetic nephropathy. Am J Physiol Renal Physiol. 2005;288(6):F1144-52.

6. Beckman JA, Goldfine AB, Gordon MB, Creager MA. Ascorbate restores endothelium-dependent vasodilation impaired by acute hyperglycemia in humans. Circulation. 2001;103(12):1618-23.

7. McVeigh GE, Brennan GM, Johnston GD, McDermott BJ, McGrath LT, Henry WR, et al. Impaired endothelium-dependent and independent vasodilation in patients with type 2 (non-insulindependent) diabetes mellitus. Diabetologia. 1992;35(8):771-6.

8. Archibald V, Cotter MA, Keegan A, Cameron NE. Contraction and relaxation of aortas from diabetic rats: effects of chronic anti-oxidant and aminoguanidine treatments. Naunyn Schmiedebergs Arch Pharmacol. 1996;353(5):584-91.

9. Koltai MZ, Hadhazy P, Posa I, Kocsis E, Winkler G, Rosen P, et al. Characteristics of coronary endothelial dysfunction in experimental diabetes. Cardiovasc Res. 1997;34(1):157-63.

10. Pieper GM, Siebeneich W. Oral administration of the antioxidant, $\mathrm{N}$-acetylcysteine, abrogates diabetes-induced endothelial dysfunction. J Cardiovasc Pharmacol. 1998;32(1):101-5.

11. Brands MW, Fitzgerald SM. Acute endothelium-mediated vasodilation is not impaired at the onset of diabetes. Hypertension. 1998;32(3):541-7.

12. Karasu C. Time course of changes in endothelium-dependent and -independent relaxation of chronically diabetic aorta: role of reactive oxygen species. Eur J Pharmacol. 2000;392(3):163-73.

13. Yousif MH, Cherian A, Oriowo MA. Endothelium-dependent relaxation in isolated renal arteries of diabetic rabbits. Auton Autacoid Pharmacol. 2002;22(2):73-82.

14. Bhardwaj R, Moore PK. Increased vasodilator response to acetylcholine of renal blood vessels from diabetic rats. J Pharm Pharmacol. 1988;40(10):739-42.
15. Altan VM, Karasu C, Ozuari A. The effects of type-1 and type-2 diabetes on endothelium-dependent relaxation in rat aorta. Pharmacol Biochem Behav. 1989;33(3):519-22.

16. Bitar MS, Wahid S, Mustafa S, Al-Saleh E, Dhaunsi GS, Al-Mulla F. Nitric oxide dynamics and endothelial dysfunction in type II model of genetic diabetes. Eur J Pharmacol. 2005;511(1):53-64.

17. Csanyi G, Lepran I, Flesch T, Telegdy G, Szabo G, Mezei Z. Lack of endothelium-derived hyperpolarizing factor (EDHF) up-regulation in endothelial dysfunction in aorta in diabetic rats. Pharmacol Rep. 2007;59(4):447-55.

18. Karasu C, Ozansoy G, Bozkurt O, Erdogan D, Omeroglu S. Antioxidant and triglyceride-lowering effects of vitamin $\mathrm{E}$ associated with the prevention of abnormalities in the reactivity and morphology of aorta from streptozotocin-diabetic rats. Antioxidants in Diabetes-Induced Complications (ADIC) Study Group. Metabolism. 1997;46(8):872-9.

19. Ajay M, Mustafa MR. Effects of ascorbic acid on impaired vascular reactivity in aortas isolated from age-matched hypertensive and diabetic rats. Vascul Pharmacol. 2006;45(2):127-33.

20. Kelly GS. Clinical applications of $\mathrm{N}$-acetylcysteine. Altern Med Rev. 1998;3(2):114-27.

21. Vries ND, Flora SD. N-acetyl-I-cysteine. J Cell Biochem. 1993; 17F:S270:7.

22. Xia Z, Nagareddy PR, Guo Z, Zhang W, McNeill JH. Antioxidant $\mathrm{N}$-acetylcysteine restores systemic nitric oxide availability and corrects depressions in arterial blood pressure and heart rate in diabetic rats. Free Radic Res. 2006;40(2):175-84.

23. Alarcon-Aguilar FJ, Calzada-Bermejo F, Hernandez-Galicia E, RuizAngeles C, Roman-Ramos R. Acute and chronic hypoglycemic effect of Ibervillea sonorae root extracts-II. J Ethnopharmacol. 2005;97(3):447-52.

24. Perez AC, Franca V, Daldegan VM Jr., Duarte ID. Effect of Solanum lycocarpum St. Hill on various haematological parameters in diabetic rats. J Ethnopharmacol. 2006;106(3):442-4.

25. Mendez JD, Balderas FL. Inhibition by L-arginine and spermidine of hemoglobin glycation and lipid peroxidation in rats with induced diabetes. Biomed Pharmacother. 2005;60(1):26-31.

26. Peschke E, Ebelt H, Bromme HJ, Peschke D. "Classical" and "new" diabetogens - comparison of their effects on isolated rat pancreatic islets in vitro. Cell Mol Life Sci. 2000;57(1):158-64.

27. Gil-del Valle L, de la CML, Toledo A, Vilaro N, Tapanes R, Otero MA. Altered redox status in patients with diabetes mellitus type I. Pharmacol Res. 2005;51(4):375-80.

28. Ramakrishna V, Jailkhani R. Oxidative stress in non-insulindependent diabetes mellitus (NIDDM) patients. Acta Diabetol. 2008;45(1):41-6.

29. Ulicna O, Vancova O, Bozek P, Carsky J, Sebekova K, Boor P, et al. Rooibos tea (Aspalathus linearis) partially prevents oxidative stress in streptozotocin-induced diabetic rats. Physiol Res. 2006;55(2):157-64.

30. Shinozaki K, Nishio Y, Okamura T, Yoshida Y, Maegawa H, Kojima $\mathrm{H}$, et al. Oral administration of tetrahydrobiopterin prevents endothelial dysfunction and vascular oxidative stress in the aortas of insulin-resistant rats. Circ Res. 2000;87(7):566-73.

31. Sena CM, Nunes E, LouroT, Proenca T, Seica RM. Endothelial dysfunction in type 2 diabetes: effect of antioxidants. Rev Port Cardiol. 2007;26(6):609-19.

32. Guo Z, Xia Z, Jiang J, McNeill JH. Downregulation of NADPH oxidase, antioxidant enzymes, and inflammatory markers in the heart of streptozotocin-induced diabetic rats by N-acetyl-L-cysteine. Am J Physiol Heart Circ Physiol. 2007;292(4):H1728-36.

33. Rodrigues AJ, Evora PRB, Schaff HV. Protective effect of N-acetylcysteine against oxygen radical-mediated coronary arteri injury. Braz J Med Biol Res. 2004;37(8):1215-24.

34. Xia Z, Kuo KH, Nagareddy PR, Wang F, Guo Z, Guo T, et al. N-acetylcysteine attenuates PKCbeta2 overexpression and myocardial hypertrophy in streptozotocin-induced diabetic rats. Cardiovasc Res. 2007;73(4):770-82. 
35. Fiordaliso F, Bianchi R, Staszewsky L, Cuccovillo I, Doni M, Laragione $\mathrm{T}$, et al. Antioxidant treatment attenuates hyperglycemia-induced cardiomyocyte death in rats. J Mol Cell Cardiol. 2004;37(5):959-68.

36. Tagami S, KondoT, Yoshida K, Hirokawa J, Ohtsuka Y, KawakamiY. Effect of insulin on impaired antioxidant activities in aortic endothelial cells from diabetic rabbits. Metabolism. 1992;41(10):1053-8.

37. Cosentino F, Eto $M$, De Paolis $P$, van der Loo B, Bachschmid M, Ullrich $V$, et al. High glucose causes upregulation of cyclooxygenase-2 and alters prostanoid profile in human endothelial cells: role of protein kinase $\mathrm{C}$ and reactive oxygen species. Circulation. 2003;107(7):1017-23.

38. Bardal S, Misurski D, Qiu X, Desai K, McNeill JR. Chronic treatment with vascular endothelial growth factor preserves agonistevoked vascular responses in the streptozotocin-induced diabetic rat. Diabetologia. 2006;49(4):811-8.

39. Bruckdorfer R. The basics about nitric oxide. Mol Aspects Med. 2005;26(1-2):3-31.

40. Nagareddy PR, Xia Z, McNeill JH, MacLeod KM. Increased expression of iNOS is associated with endothelial dysfunction and impaired pressor responsiveness in streptozotocin-induced diabetes. Am J Physiol Heart Circ Physiol. 2005;289(5):H2144-52.

41. Alnaeb ME, Thompson CS, Seifalian AM, Hamilton G, Mikhailidis DP. Regional differences in the expression of nitric oxide synthase and specific receptors in the vascular tissues of control and diabetic rabbits: a pilot study. In Vivo. 2007;21(6):1069-74.

42. Bojunga J, Dresar-Mayert B, Usadel KH, Kusterer K, Zeuzem S. Antioxidative treatment reverses imbalances of nitric oxide synthase isoform expression and attenuates tissue-cGMP activation in diabetic rats. Biochem Biophys Res Commun. 2004;316(3):771-80.

43. Palmer AM, Thomas CR, Gopaul N, Dhir S, Anggard EE, Poston $\mathrm{L}$, et al. Dietary antioxidant supplementation reduces lipid peroxidation but impairs vascular function in small mesenteric arteries of the streptozotocin-diabetic rat. Diabetologia. 1998;41(2):148-56.

44. Fitzgerald SM, Brands MW. Nitric oxide may be required to prevent hypertension at the onset of diabetes. Am J Physiol Endocrinol Metab. 2000;279(4):E762-8.

45. Carvalho Leone AF, Coelho EB. Effects of prostanoids on phenylephrine-induced contractions in the mesenteric vascular bed of rats with streptozotocin-induced diabetes mellitus. Life Sci. 2004;76(3):239-47.

46. Peredo HA, Rodriguez R, Susemihl MC, Villarreal I, Filinger E. Long-term streptozotocin-induced diabetes alters prostanoid production in rat aorta and mesenteric bed. Auton Autacoid Pharmacol. 2006;26(4):355-60. 